\title{
TEXTO E TEXTUALIDADE NA ERA DIGITAL ${ }^{1}$
}

Text and Textuality in the Digital Era

\author{
Walter Vieira BARROS (UFCG) ${ }^{2}$
}

RESUMO: Em muitas das transformações pelas quais tem passado o mundo contemporâneo, as novas tecnologias têm desempenhado papel importante, desafiando a base epistemológica a partir da qual pensamos a construção do conhecimento. Considerando esse contexto, o objetivo deste artigo é problematizar as noções de texto e de textualidade na era digital. A partir de um levantamento teórico, nos fundamentamos, principalmente, na revisitação que Costa Val $(2000$, 2004) faz ao conceito de textualidade para, então, discutirmos as fragilidades e as possíveis ampliações dos entendimentos acerca do que é um texto e dos fatores de textualidade, considerando a imprecisão e a fluidez da linguagem e dos sentidos, potencializadas pelas tecnologias digitais.

PALAVRAS-CHAVE: Tecnologias digitais; Texto; Textualidade.

ABSTRACT: In many of the changes that the contemporary world has been through, the new technologies play a key role, challenging the conventional epistemology that underpins the way we understand knowledge construction. Considering this context, this paper aims at problematizing the notions of text and of textuality in the digital era. Based on a literature review, we discuss, firstly relying on the revisiting of the concept of textuality by Costa $\mathrm{Val}(2000,2004)$, the fragilities and the possible expanding of what is considered a text and the textuality standards, taking into account the inaccuracy and the fluidity of language and of meanings, which are potentialized by the digital technologies.

KEYWORDS: Digital technologies; Text; Textuality.

\section{INTRODUÇÃO}

As tecnologias digitais "impuseram-se como um elemento cada vez mais importante de mudança nos modos de viver, pensar e comunicar" (PISCHETOLA, 2016, p. 9). Elas são resultados de transformações sociais mais amplas, ao mesmo tempo que também geram mudanças na "comunicação e nas formas de interação [...] cujas consequências se fazem notar nos modos de construção de conhecimento, nas interações sociais, nas formas de ler e perceber o mundo" (MONTE MÓR, 2010, p.

\footnotetext{
${ }^{1}$ Este artigo é parte das discussões da pesquisa de mestrado em andamento (com defesa prevista para julho/2019) do autor deste texto, porém, direcionadas à problematização das noções de texto e de textualidade na era digital.

${ }^{2}$ Mestrando do Programa de Pós-Graduação em Linguagem e Ensino (PPGLE) da Universidade Federal de Campina Grande (UFCG). Licenciado em Letras - Língua Inglesa (2017) pela UFCG. Campina Grande-PB. Email: waltervieirabarros@gmail.com
} 
REVISTA X, Curitiba, volume 14, n.3, 174-186, 2019.

469), constituindo uma nova mentalidade (new mindset).

Segundo Lankshear e Knobel (2007), mentalidade se refere a um ponto de vista ou a uma perspectiva a partir da qual experienciamos o mundo; interpretamos, construímos sentidos e agimos. Ao pensar sobre a sociedade contemporânea, os autores identificam duas mentalidades.

A primeira, denominada 'físico-industrial', assume que a sociedade contemporânea continua igual ao que era há algumas décadas, porém mais "tecnologizada". Dessa forma, entende-se que não houve mudanças na sociedade, apenas uma maior presença das Tecnologias Digitais da Informação e Comunicação (TDIC), que ajuda a realizar de forma mais rápida o que já se fazia. Nessa perspectiva, as TDIC seriam uma nova roupagem ou um novo suporte para práticas que continuam as mesmas de uma conjuntura social anterior, em que as coisas eram realizadas por meio de repetições, desenvolvimento de rotinas, treinamentos etc. baseados em "suposições duradouras sobre corpos, materiais, propriedades e formas de posse, princípios e técnicas industriais, textos físicos, negociações face a face"3 (LANKSHEAR; KNOBEL, 2007, p. 10, tradução minha ${ }^{4}$ ).

Na segunda, denominada 'ciberespaço-pós-industrial', o mundo contemporâneo é visto como diferente do que era há algumas décadas e que essas mudanças continuam aumentando, de forma que, em alguns anos, a sociedade apresentará transformações que a diferenciará do que é hoje. Entende-se, de acordo com essa segunda mentalidade, que as mudanças na contemporaneidade são ontológicas e relacionadas ao desenvolvimento das TDIC, ao possibilitarem que "pessoas imaginem e explorem novas maneiras de fazer coisas e novas maneiras de ser/estar" ${ }^{\text {"5 }}$ no mundo (LANKSHEAR; KNOBEL, 2007, p. 10), ao invés de entender as tecnologias como ferramentas que apenas possibilitam que algo convencional possa ser realizado de uma forma mais "tecnologizada".

Com base no que foi exposto, percebe-se que, de forma geral, a base epistemológica a partir da qual se pensa o conhecimento, conforme explicam Lankshear e Knobel (2003), tem se tornado obsoleta e tem sido "desafiada” pelas novas práticas da

3 “[...] longstanding assumptions about bodies, materials, property and forms of ownership, industrial techniques and principles, physical texts, face to face dealings [...]". (LANKSHEAR; KNOBEL, 207, p. 10).

${ }^{4}$ Todas as traduções presentes neste artigo foram feitas pelo autor. Feito este esclarecimento, não utilizarei nas próximas traduções a expressão "tradução minha".

5 "[...] people imagining and exploring new ways of doing things and new ways of being [...]". (LANKSHEAR, KNOBEL, 2007, p. 10). 
REVISTA X, Curitiba, volume 14, n.3, 174-186, 2019.

contemporaneidade, especialmente com o advento das tecnologias digitais. Os autores ressaltam a necessidade de desenvolvimento de epistemologias digitais - termo guardachuva para se referir às questões e aos aspectos da sociedade digital.

Essas novas práticas, que desafiam as bases epistemológicas convencionais, ao se constituírem por mudanças ontológicas, nos fazem (re)pensar, na área da língua(gem) e ensino de línguas, acerca do que se entende por texto e por textualidade. Dessa forma, o objetivo deste artigo é problematizar os conceitos de texto e de textualidade na era digital, uma vez que tais conceitos ainda parecem estar arraigados, principalmente no âmbito escolar, ao que Lankshear e Knobel (2007) denominaram de mentalidade 'físicoindustrial'.

Ao problematizar tais conceitos, não pretendo sugerir que os argumentos a serem abordados apenas dizem respeito às produções textuais realizadas em meio digital. Acredito que as tecnologias digitais evidenciam aspectos que precisam ser discutidos, mas que dizem respeito aos conceitos de texto e de textualidade, independentemente da realização/materialização do texto precisar ou não das tecnologias digitais.

O presente artigo está estruturado em três seções, além desta Introdução e das Considerações finais. Essas seções problematizam, respectivamente, os conceitos de texto e de textualidade, bem como os fatores de textualidade, considerando o contexto sócio-histórico contemporâneo que está, cada vez mais, constituído por tecnologias digitais.

\section{TEXTO}

Conforme ressalta Koch (2003), a concepção de texto depende de uma concepção de língua. De forma geral, segundo Hall (1997), há três abordagens para se tentar compreender a língua ${ }^{6}$ : a) a reflexiva (reflective), que entende a língua como um espelho que reflete o significado já existente no mundo - o verdadeiro significado; b) a intencional (intentional), que entende a língua como um meio de comunicação dos sentidos impostos/criados pelo indivíduo; e c) a construcionista (constructionist), que entende a língua como um produto social onde os significados são construídos.

Considerando a primeira abordagem apresentada por Hall (1997), temos uma

\footnotetext{
${ }^{6}$ Utilizo o termo "língua" em conformidade com as discussões de Hall (1997), em que o autor aborda language em um sentido mais amplo, podendo ser traduzido como língua(gem).
} 
REVISTA X, Curitiba, volume 14, n.3, 174-186, 2019.

concepção reflexiva (no sentido de reflexo, isto é, de refletir algo tal como ele é) da língua. Nessa concepção, o texto é entendido como um produto estável que reflete o pensamento do autor; o texto reflete a representação mental e as intenções de seu produtor. Ao leitor, cabe captar tal reflexo/representação mental (KOCH, 2003).

A segunda abordagem, a intencional, demonstra uma concepção de língua enquanto código, mero instrumento de comunicação. Dessa forma, o texto é entendido como produto estável e explícito, codificado por um autor/codificador. Ao leitor/decodificador, basta o conhecimento do código para decodificar o texto e, assim, ter acesso ao sentido ali codificado (cf. HALL, 1997; KOCH, 2003).

Por fim, Hall (1997) apresenta a abordagem construcionista, em que a língua é entendida como prática de significação. De acordo com o autor, o significado não é natural, o sentido não é inerente às "coisas", mas é resultado de uma prática de significação, prática que produz sentidos e faz as "coisas" significarem. O sentido não está no objeto, nem está na palavra, ele é fixado socialmente.

Nessa perspectiva, o leitor não pode ser concebido como sujeito passivo, cuja responsabilidade é decodificar, encontrar, captar, identificar algo que já estaria no texto; fruto das intenções de um autor. Isso porque

[...] há uma necessária e inevitável imprecisão na língua(gem). $\mathrm{O}$ sentido/significado que percebemos como espectadores, leitores ou audiência nunca é exatamente o sentido/significado que foi dado pelo falante ou escritor ou outros espectadores. [...] o leitor é tão importante quanto o escritor no processo de produção de sentidos ${ }^{7}$. (HALL, 1997, p. 32-33).

É nessa perspectiva que entendo ser preciso rediscutir a concepção de texto, uma vez que as concepções apresentadas (cf. KOCH, 2003) - ainda dominantes - parecem não considerar a imprecisão da língua e dos sentidos. Tal imprecisão é ainda mais destacada ao considerarmos a sociedade digital em que vivemos, contribuindo para a contestação dessas concepções mainstream.

Barton e Lee (2015) explicam que, ao tratar das tecnologias digitais, é importante entender que elas também são parte de transformações sociais, foram/são construídas socialmente e, portanto, não são ferramentas neutras. Além disso, os autores ressaltam o papel fundamental da linguagem nessas mudanças do mundo

\footnotetext{
7 " [...] there is a necessary and inevitable imprecision about language. The meaning we take, as viewers, readers or audience, is never exactly the meaning which has been given by the speaker or writer or by other viewers. [...] the reader is as important as the writer in the production of meaning". (HALL, 1997, p. 32-33).
} 
REVISTA X, Curitiba, volume 14, n.3, 174-186, 2019.

contemporâneo, "que são, antes de tudo, transformações de comunicação e de construção de sentidos" (BARTON; LEE, 2015, p. 13). Assim, percebe-se a importância de conceber as tecnologias (digitais) e a linguagem como elementos constitutivos de práticas sociais, que influenciam e são influenciados pelas transformações da sociedade atual. Isso implica compreender que as "produções textuais (no sentido duplo de autoria e leitura de textos)" (MENEZES DE SOUZA, 2011, p. 133), digitais ou não, são construídas sócio-historicamente nas e pelas comunidades heterogêneas das quais pertencemos e somos por elas constituídos.

Dialogando com a abordagem construcionista, em que a língua é entendida como prática de significação, a perspectiva dos letramentos, mais especificamente pelo viés do letramento crítico, entende que a "linguagem tem natureza política, em função das relações de poder nela presentes” (MONTE MÓR, 2013, p. 42) e que configura representações da realidade, posições culturais, ideologias e discursos em textos (CERVETTI; PARDALES; DAMICO, 2001; LUKE; FREEBODY, 1997).

Em uma epistemologia digital, o texto apresenta-se "amalgamado por meio da aproximação e justaposição de formas de expressão inovadoras, dentre as quais textos, imagens, sons, gráficos, emoticons, hyperlinks, cujas significações, vale dizer, sofrem variações culturais" (DUBOC, 2012, p. 77, grifo da autora).

Como é possível perceber, está sendo discutido noções de texto que são contestadas frente à fluidez e à imprecisão da língua e dos sentidos, ressaltados na era digital. Mas, ainda, não foi apresentado uma concepção de texto. Na tentativa de, ao menos, apresentar direcionamentos que sinalizem uma noção de texto passível de diálogo com a complexidade da língua, que não é inerente à era digital, mas ressaltada por ela, me fundamento, principalmente, em Barros (2016), Dias (2016) e Nascimento (2008).

Primeiramente, buscando uma melhor compreensão de texto na era digital, entendo, com base em Buzato (2006), que seja preciso evitar a noção de "suporte", geralmente designada às tecnologias digitais. Isto é, deslocar-se da concepção de texto como produto estável e explícito que apenas se apresenta em um outro "suporte" que não é o papel (livro, jornal, revista etc). A noção de suporte pode levar as discussões em direção a uma descrição detalhada e dicotômica, resultando em uma polarização entre o impresso e o digital.

De acordo com Barros (2016), as tecnologias, bem como as práticas sociais com 
REVISTA X, Curitiba, volume 14, n.3, 174-186, 2019.

elas possibilitadas, são parte das condições de produção de sentidos na atualidade. Isso aponta para a compreensão de que tecnologia e linguagem são indissociáveis, uma vez que estão em uma relação constitutiva.

As "produções textuais (no sentido duplo de autoria e leitura de textos)" (MENEZES DE SOUZA, 2011, p. 133) são construídas

\begin{abstract}
para e a partir de dispositivos que são construídos para funcionar numa sociedade na qual tem a tecnologia e a escrita como elementos constitutivos. Com um pouco mais de especificidade, a forma-material, isto é, a forma encarnada na história para produzir sentido com a qual o sujeito estabelece uma relação de produção é outra. Não é o lápis, o papel e a borracha [...]. (BARROS, 2016, p. 183-184).
\end{abstract}

Dias (2016, p. 166-167) se fundamenta em Orlandi (2001), ao defender que a tecnologia pode ser vista como meio, desde que se entenda que o meio nunca é neutro e sim "parte constitutiva do sentido, bem como a maneira com que ele se formula, se constitui e circula". Dessa forma, a autora trata as tecnologias digitais e as produções digitais como materialidade digital que é parte dos processos de significação. Por fim, Dias (2016) afirma pensar o texto "em sua materialidade (com sua forma, suas marcas e seus vestígios); como historicidade significante e significada (e não como 'documento' ou 'ilustração')" (ORLANDI, 2001, p. 12 apud DIAS, 2016, p. 170).

Diante do que fora discutido até o momento, e com base em Nascimento (2008), ao argumentar que um texto é uma organização de signos, marcas e vestígios, cuja força está na inesgotabilidade, uma vez que pode "dizer coisas jamais previstas por seu autor" (NASCIMENTO, 2008, p. 128), acredito que podemos conceber 'texto', na era digital, como uma organização sígnica-vestigial potencial de significação.

\title{
TEXTUALIDADE
}

Partindo de uma base estruturalista, a Linguística Textual defendeu por certo tempo que os textos apresentavam algumas características que lhes possibilitavam ser lidos/interpretados. Essas características eram apontadas como definidoras das qualidades que um texto deveria ter (cf. NOVAIS, 2009).

O conjunto dessas características, ou fatores, constituem o conceito de textualidade, termo cunhado por Rovbert-Alain de Beaugrand e Wolfgang Dressler, no livro Introduction to Text Linguistics em 1981 (cf. COSTA VAL, 2000, 2004). A textualidade seria, portanto, um conjunto de fatores - coesão, coerência, intencionalidade, informatividade, aceitabilidade, situacionalidade e intertextualidade - 
REVISTA X, Curitiba, volume 14, n.3, 174-186, 2019.

"que fazem com que um texto seja um texto, e não apenas uma sequência de frases ou palavras" (COSTA VAL, 2004, p. 2).

De acordo com Costa Val (2000), pode-se perceber três momentos ${ }^{8} /$ perspectivas $^{2}$ nos estudos da Linguística Textual: a) estudos com foco na análise transfrástica (correferência, emprego de artigo, correlação entre os tempos e modos verbais etc.), cujo foco era o que veio a se denominar de coesão; b) estudos que vão além da frase e passam a considerar a significação do texto como um todo. O interesse dos teóricos era o de construir gramáticas do texto - que descrevessem e explicassem a capacidade de produzir, interpretar e reconhecer textos coerentes -, focalizando a coerência; c) estudos com foco na construção de teorias do texto - a significação não está no texto, mas na relação entre texto, contexto e falantes - cujo foco está na dimensão sociocomunicativa, em que a coerência depende da identificação, pelos parceiros, do ato ilocutório ${ }^{9}$.

Essas três perspectivas apresentadas pela autora têm por base a obra de MariaElisabeth Conte publicada em 1977. Porém, ela explica que autores mais recentes como Michael A. K. Halliday e Ruqaiya Hasan, por exemplo, buscam uma integração entre o primeiro e o terceiro momento, mas que, embora considerassem a dimensão sociocomunicativa, entendiam a coesão como definidor da textualidade. No Brasil, Luiz Antônio Marcuschi, Ingedore Grünfeld Villaça Koch e Luiz Carlos Travaglia se alinham a segunda perspectiva, ao entenderem a coerência como foco dos estudos, uma vez que ela daria origem à textualidade (cf. COSTA VAL, 2000).

De acordo com Costa Val (2004, p.1), qualquer produção textual que

numa dada circunstância, pareça "sem pé nem cabeça", incompreensível, inadequada, inaceitável, para determinado grupo, pode ser perfeitamente entendida e considerada como sem qualquer problema por outros interlocutores, noutra situação, e, para eles, funcionar plenamente como texto. Isso quer dizer que o sentido não está no texto, não é dado pelo texto, mas é produzido por locutor e alocutário a cada interação, a cada "acontecimento" de uso da língua.

A noção de textualidade como algo que está no texto parece não se sustentar. Isso fica mais evidente se tentássemos julgar a qualidade de um texto, ou o próprio status de texto, avaliando os fatores de textualidade "presentes" em produções textuais

\footnotetext{
${ }^{8}$ Não são, necessariamente, momentos cronológicos, uma vez que, conforme explica Costa Val (2000), esses momentos ou perspectivas também ocorriam concomitantemente.

9 “[...] ato que o realizado pelo locutor quando pronuncia um enunciado em determinadas condições comunicativas e com intenções (ordenar, avisar, criticar, perguntar, convidar, ameaçar, etc.) Num ato ilocutório, a intenção comunicativa de execução vem associada ao significado de determinado enunciado, e a ação do ouvinte (interlocutor)”. (CASTIM, 2017, p. 89-90).
} 
REVISTA X, Curitiba, volume 14, n.3, 174-186, 2019.

digitais, que são cada vez mais multimodais, maleáveis, móveis, abertas.

Por isso, entendo que a revisitação que Costa Val $(2000,2004)$ faz ao conceito de textualidade ajuda-nos a melhor entendê-la na era digital. De acordo com a autora, a textualidade não está no texto, ela é uma realização humana; a textualidade se constrói no processo de interpretação. A autora revisita o conceito levando em consideração, bem como ampliando, as discussões de Rovbert-Alain de Beaugrand e Wolfgang Dressler, que se alinham à terceira perspectiva dos estudos da Linguística Textual. Para melhor entendermos como a textualidade se constrói no processo, uma vez que não está (nem estará) pronta, os fatores de textualidade serão discutidos, brevemente, a seguir.

\section{(RE)PENSANDO OS FATORES DE TEXTUALIDADE}

De acordo com Costa Val (2000, 2004), embora as discussões que se alinham à terceira perspectiva de estudos da Linguística Textual tenham se voltado para o processo, elas não tiveram grande repercussão entre os leitores. A autora explica que, mesmo fundamentando-se em autores dessa terceira perspectiva, pesquisadores continuam focalizando o produto e exemplifica isso fazendo referência à obra de sua autoria Redação e Textualidade, publicada em 1991.

Acredito que os sete fatores de textualidade não deveriam ser entendidos como separados e ordenados em uma sequência linear, mas como mutuamente constitutivos. Os fatores 'coesão' e 'coerência', foco de muitos trabalhos que discutem a existência deste fator em detrimento daquele para definir um texto como sendo texto, na revisitação de Costa Val (2000, 2004), são entendidos como construídos no processo de interpretação e não como inerentes ou que precisam estar presentes no texto.

De acordo com a autora, esses fatores são sinalizados pelo autor, mas não significa que a coerência e a coesão já estão produzidas nos textos. Há sinalizações, elementos, vestígios configurados pelo autor, mas a coesão e a coerência são construídas no processo de interpretação do leitor (assim como o texto é resultado de um processo de interpretação do autor).

Se considerarmos as produções textuais digitais, os sinalizadores de coesão são os links, por exemplo. Tais links podem (ou não) ser percebidos pelo leitor/usuário que, por sua vez, poderá (ou não) construir coesão e, assim, estabelecer (ou não) relações entre os elementos e construir (ou não) sentido(s) a partir do texto, atribuindo-lhe (ou não) coerência. Também, há de se admitir que nessas relações estabelecidas pelo leitor, 
REVISTA X, Curitiba, volume 14, n.3, 174-186, 2019.

a coesão e a coerência podem ser atribuídas/construídas a partir de outros vestígios encontrados nos textos e que não foram intencionalmente configurados, pelo autor, para tal função.

Isso nos remete aos fatores 'intencionalidade' e 'aceitabilidade'. Entendo que esses fatores ficam "fragilizados", uma vez que, complementando o que fora discutido no parágrafo anterior, relações outras e vestígios outros podem ser entendidos como sinalizadores de coesão e/ou de coerência. Com isso, sentidos outros, jamais previstos pelo autor, podem ser construídos (cf. NASCIMENTO, 2008). Logo, não parece se sustentar a ideia de intenção do autor/produtor e da aceitabilidade do leitor/receptor, que deveria estabelecer uma relação entre suas expectativas, a intenção do autor e a situação em que ocorre o texto.

Também concordo com Costa Val (2000), ao defender uma ampliação da noção do fator 'situacionalidade'. Para a autora, a situacionalidade não deve ser entendida apenas como uma situação imediata, necessária para que o leitor a relacione com as intenções do autor para atribuir ou não aceitabilidade, mas considerar a situacionalidade em noção ampla, isto é, considerar o contexto socio-histórico-cultural em que ocorre a produção textual e a leitura.

Pensando nos textos produzidos nos/para o ambiente digital, percebe-se que essa "fragilidade" dos fatores 'intencionalidade' e 'aceitabilidade', bem como a necessidade de expansão da situacionalidade são ressaltadas. Isso porque tais textos tendem a ser bastante não-lineares e possibilitam, de forma mais explicita que os textos impressos, conexões que fogem à intenção do autor. Contribuindo para essa problematização, as Orientações Curriculares para o Ensino Médio (BRASIL, 2006), ao tratarem de leitura de textos digitais, discutem a ideia de trajetos de leitura e que, ao final, o leitor assumiria a responsabilidade de "autor" do texto lido.

Portanto, entende-se que o sentido não é construído em um vácuo, não é algo neutro ou objetivamente construído e expresso conforme intenções de um indivíduo, mas construído “[...] em um contexto de relações de poderes, de relações sociais e históricas"10 (CERVETTI; PARDALES; DAMICO, 2001, p. 6). A autoria e a leitura, embora pareçam "atos individuas e/ou voluntariosos, são constituídas sóciohistóricamente pelas comunidades às quais se pertence e pelas suas histórias anteriores da produção de significação" (MENEZES DE SOUZA, 2011, p. 134-135).

10 "[...] in the context of social, historic, and power relations". (CERVETTI; PARDALES; DAMICO 2001, p. 6). 
REVISTA X, Curitiba, volume 14, n.3, 174-186, 2019.

Isso nos remete ao fator 'intertextualidade'. Esse fator diz respeito às relações que um texto faz com outros textos. Essa característica é bem ressaltada nos textos digitais que se constituem visualmente por vários textos e/ou com links que direcionam a textos diversos. No entanto, como explica Costa Val (2004), o autor, por exemplo, talvez não (re)conheça os outros textos que constituem o seu texto.

Acredito, partindo da asserção da autora mencionada, que não seja possível (o autor e/ou o leitor) dar conta de uma totalidade fechada de quais/quantos textos estão envolvidos em uma produção textual. Isso aponta para o que Costa Val (2000) argumenta acerca da limitação da noção de textualidade: não considerar o que vai além da referenciação ou identificação explícita de outros textos, isto é, os aspectos sociais, históricos e culturais, as condições de produção que constituem o texto e os sentidos (na perspectiva do autor e do leitor).

Para além da materialidade (digital ou não), é preciso entender que o texto, o autor e o leitor se inserem como um elo em uma cadeia e, portanto, se constituem dialogicamente com outros textos e sentidos. O autor não é um Adão bíblico. (cf. BAKHTIN, 1997). Nessa perspectiva de entender que o autor não é o criador primeiro dos sentidos e que tanto o autor como leitor constroem sentidos com base nas comunidades em que esses autores/leitores se situam/constituem sócio-historicamente, Menezes de Souza (2011) recorre ao conceito de genealogia. Como explica o autor,

\footnotetext{
o conceito de genealogia vem das teorias de Nietzsche e Foucault e não significa chegar a um origem derradeira do significado; significa sim um processo de reconhecimento e análise das produções textuais (no sentido duplo de autoria e leitura de textos) anteriores nas quais um determinado leitor/autor participou ou as quais foi exposto; significa reconhecer que enquanto leitores/autores de textos somos frutos de nossas histórias de leitura/escrita, historias essas sempre sociais e coletivas. [...], mesmo quando se escreve ou se lê individualmente, está-se usando palavras, significados, textos e leituras que antecederam e que constituíram tanto o momento atual de produção de texto quanto o próprio autor/leitor". (MENEZES DE SOUZA, 2011, p. 133).
}

Tanto a autoria como a leitura de textos se inserem como elos em uma cadeia (BAKHTIN, 1997) ou, poderíamos problematizar, em cadeias diferentes (que diferem em maior ou menor grau). Dessa forma, também se coloca em xeque o fator 'informatividade'. Se estamos entendendo que o sentido é construído na produção/leitura do texto, não cabe discutir o nível de informatividade (informações novas) presente no texto. Esse "nível" não diz respeito ao texto, mas ao sujeito que o lê/produz e sua história. 
REVISTA X, Curitiba, volume 14, n.3, 174-186, 2019.

Como é possível perceber, não há uma fronteira bem delimitada entre esses fatores de textualidade, principalmente com as problematizações feitas a partir das discussões de Costa Val (2000, 2004), muito menos uma hierarquização ou uma sequência linear entre eles. Por isso, entendo que o foco da textualidade não está no fator de coesão, nem no fator de coerência, como em perspectivas anteriores, mas na relação constitutiva entre todos os fatores e as condições de produção no processo de construção de sentidos.

\section{CONSIDERAÇÕES FINAIS}

De acordo com Lankshear e Knobel (2003), é preciso desenvolver epistemologias digitais, uma vez que a base epistemológica a partir da qual se pensa o conhecimento tem sido contestada frente às novas práticas na era digital. Considerando esse contexto, este artigo teve como objetivo problematizar os conceitos de texto e de textualidade na era digital.

As discussões apresentadas reforçam a inevitável imprecisão da língua(gem) a qual Hall (1997) se refere. Com as tecnologias digitais, há uma desestabilização das hierarquias entre autor e leitor, colocando ambos como igualmente importantes na construção de sentidos. Dessa forma, questiona-se a ideia de um sentido único e já pronto no texto, bem como as características preestabelecidas como necessárias para validar a qualidade de um texto e o próprio status de texto.

A textualidade e o que se considera como texto é algo construído no processo de interpretação que varia de acordo com o contexto sócio-histórico-cultual dos sujeitos envolvidos. Quanto mais diferentes forem esses contextos e as comunidades às quais pertencem o autor e o leitor, por exemplo, maior a possibilidade de construções de sentidos diferentes.

\section{REFERÊNCIAS}

BAKHTIN, M.M. Os gêneros do discurso. In: Estética da criação verbal. Tradução de Maria Emsantina Galvão G. Pereira. 2. ed. São Paulo: Martins Fontes, 1997. p. 277-326.

BARROS, R.C.B. Tecnologias de linguagem e existência: a escrita afetada pela materialidade digital. Fragmentum. Santa Maria: UFSM, n. 48, p. 175-189, jul./dez. 2016.

BARTON, D.; LEE, C. Linguagem no mundo digital. In: Linguagem online: textos e práticas digitais. Tradução: Milton Camargo Mota. São Paulo: Parábola Editorial, 2015. p. 11-28. 
REVISTA X, Curitiba, volume 14, n.3, 174-186, 2019.

BRASIL. Secretaria de Educação Básica. Orientações curriculares para o ensino médio: Linguagens, códigos e suas tecnologias. Brasília: MEC/SEB, v. 1, 2006. p. 85124.

BUZATO, M. E.K. Letramentos digitais e formação de professores. In: Anais do III Congresso Ibero-Americano EducaRede. São Paulo: CENPEC, p. 1-7, 2006.

CASTIM, F. John Austin e os atos de fala. Ágora Filósofia. Pernambuco: UNICAP, v. 17, n. 1, p. 84- 95, 2017.

CERVETTI, G.; PARDALES, M.J.; DAMICO, L.S. A tale of differences: comparing the traditions, perspectives and educational goals of critical reading and critical literacy. Reading Online, v. 4, n. 9, 2001.

COSTA VAL, M.G. Texto, textualidade e textualização. Pedagogia Cidadã: Cadernos de Formação. São Paulo: UNESP, p. 113-128, 2004.

Repensando a textualidade. In: AZEREDO, J. C. (Org.). Lingua portuguesa em debate: conhecimento e ensino. Petrópilos, RJ: Vozes, 2000. p. 34-51.

DIAS, C. A materialidade digital da mobilidade urbana: espaço, tecnologia e discurso. Línguas e Instrumentos Linguísticos, São Paulo: Unicamp, n. 37, p. 157-175, jan./jun. 2016.

HALL, S. (Org.). Representation: cultural representation and signifying practices. London/Thousand Oaks/New Delhi: Sage/Open University, 1997.

DUBOC, A.P.M. Atitude curricular: letramento crítico nas brechas da formação do professor de inglês. 258f. Tese (Doutorado em Letras). Universidade de São Paulo, São Paulo, 2012.

LANKSHEAR, C.; KNOBEL, M. Sampling "the new" in new literacies. In: KNOBEL, M.; LANKSHEAR, C. (Eds.). A new literacies sampler. New York: Peter Lang Publishing, 2007. p. 1-24.

New literacies: changing knowledge and classroom learning. Buckingham: Open University Press, 2003.

LUKE, A.; FREEBODY, P. Critical literacy and the question of normativity. In: MUSPRATT, S.; LUKE, A.; FREEBODY, P. (Eds.). Constructing critical literacies. St. Leonards: Hampton, Press, 1997.

KOCH, I.G.V. Desvendando os segredos do texto. 2. ed. São Paulo: Cortez, 2003.

MENEZES DE SOUZA, L.M.T. Para uma redefinição de letramento crítico: conflito e produção de significação. In: MACIEL, R.F.; ARAUJO, V.A. (Orgs.). Formação de professores de línguas: ampliando perspectivas. Jundiaí: Paco Editorial, 2011. p. 128140.

MONTE MÓR, W. Crítica e letramentos críticos: reflexões preliminares. In: ROCHA, C.H; MACIEL, R.F. (Orgs.). Lingua estrangeira e formação cidadã: por entre discursos e práticas. Campinas: Pontes, 2013. p. 31-50. 
MONTE MÓR, W. Multimodalidades e comunicação: antigas novas questões no ensino de línguas estrangeiras. Letras \& Letras, Uberlândia - MG, v. 26, p. 469-478, 2010.

NASCIMENTO, E. Texto, textualidade, contexto. In: SIGNORINI, Inês (Org.). [Re]discutir texto, gênero e discurso. São Paulo: Parábola, 2008. p. 109-131.

NOVAIS, A.E. Lidando com experiências genuinamente digitais: leitura, textualidade e design de interação na leitura da interface gráfica de usuário. In: III Encontro Nacional sobre Hipertexto, Belo Horizonte, MG, 2009.

PISCHETOLA, M. Inclusão digital e educação: a nova cultura da sala de aula. Petrópolis: Editora Vozes; Rio de Janeiro: Editora PUC-Rio, 2016. 